\title{
Ergonomic Prospects: Tractor Operator Workplace Design
}

\author{
Yadav Rajvir ${ }^{1 *}$ and Jakasania RG $^{2}$ \\ ${ }^{1}$ Professor \& Head \& Department of Farm Engineering, College of Agriculture, Junagadh \\ Agricultural University, India \\ ${ }^{2}$ Senior Research Fellow, IDP Cell, College of Agricultural Engineering and Technology, \\ Junagadh Agricultural University, India
}

Editorial

Volume 4 Issue 5

Received Date: September 28, 2020

Published Date: October 14, 2020

DOI: $10.23880 /$ eoij- 16000255

*Corresponding author: Rajvir Yadav, Professor \& Head, Department of Farm Engineering, College of Agriculture, Junagadh Agricultural University, Junagadh-362001,Gujarat, India, Email: ryadav61@gmail.com

\section{Editorial}

Human engineering or ergonomics deals with the aspect of man-machine system which means engineering the product or machine to fit the operator. Ergonomics effectively became a field of specialization in recent times, because now the objective is to have maximum operational efficiency, which lead to multi-disciplinary approach. There is a minor difference between two approaches, first approach deals mainly with combination of man- machine system, whereas the second approach deals with wellbeing of the individual concerned.

The ergonomic aspects during application in agricultural equipment are very important and helpful to the operator. Operator performance is also depending on a physiological as well as psychological fatigue. The objective of ergonomics is to improve efficiency, human comfort as well as safety of the operator. If ergonomic is not consider in the design of agricultural equipment, then the performance of the system will be poor and the effective working time will be reduced.

Farming is most tedious and hard occupational sectors compared to other sector. The fact is that reporting of agricultural tractor accidents and injuries is commonly, studies still show that agriculture related fatalities rank high even in developed countries. Closer scrutiny of the survey data showed that farm tractors are the major cause of occupational fatalities in the agricultural sector.

Tractor is a basic power source for farmers. So, that the consideration of human factors is required in design of the modern tractor. These factors, when properly incorporated in design, allow the operator to perform many complex tasks with efficiency, safety, and a minimum of fatigue. Overall, human aspects include such items as riding comfort, visibility, location and arrangement of controls, ease of operating controls, design for thermal comfort, and sound control. The ergonomic design of tractor operator seat and workplaces is an effective method for improving operator comfort. The seat design characteristics comprise of static and dynamic characteristics. The static characteristic of the tractor seat refers to the relation of comfort to seat construction type and its geometric parameters and the physiological features.

It is generally recognized that to minimize discomfort, fatigue and the possibility of damage to the back whilst seated, the spinal column should maintain its normal curvature as found in the standing position. The main body support is provided by the seat pan, taking between 65 and $75 \%$ of the body weight, which is transferred via the ischial tuberosity and to a lesser extent the surrounding tissues. The working envelopes for hands and legs to be optimum and maximum as per the need of the working space respectively. Distances from SRP/SIP in horizontal as well as vertical plane is also must as per need of the anthropometric data of the user's population. The linear dimensions of tractor seat must fit those of the most likely user population. This by now is axiomatic. Therefore, seat characteristics such as seat pan length, width and tilt, backrest height angle and slope need to be designed considering anthropometric data of most likely user population i.e. tractor operators.

A number of principles are followed for a tractor seat and tractor workplace design.

- The type and dimensions of the seat are related to the goal for sitting.

- The dimensions of the seat should fit the appropriate anthropometric dimensions of the sitter.

- The seat should be designed to provide support and stability for the operator. 
- The seat should be designed to allow the operator to vary his posture, but the fabric needs to resist slipping when there is fidgeting.

- Backrests, particularly prominent in the lumber region, will reduce the stress on this part of the spinal column.

- The seat pan needs sufficient padding and firmness to help to distribute the body weight Pressures from the ischial tuberosities.

- Working envelopes by hand and leg for maximum \& optimum working spaces.
Sitting is often considered to a natural posture, relieving the operator of the need to maintain an upright position. A tractor seat which requires the operator to adopt certain postures can create at the least muscular fatigue due to the static loads placed on the spinal and other muscles. In most of the tractors (in India as well as world trend), manufacturers are using four bar linkage suspended seat now a days but it should be designed to accommodate the size and shape of at least $90 \%$ the tractor operator's population, based on anthropometric data. 